\title{
SENSITIVITY PATTERNS OF SOME FLOWERING PLANTS AGAINST SALMONELLA TYPHI AND PSEUDOMONAS AERUGINOSA DR.S.JENIFER
}

ASST.PROFESSOR DEPARTMENT OF BIOTCHNOLOGY, BON SECOURS COLLEGE FOR WOMEN, ABTRACT THANJAVUR, TAMILNADU

The medicinal plants have been collected form wild resources and only some species used in larger quantities are cultivated systematically. Many medicinal plants, which were ignored in the past years, but the number of plants still formed in the wild is progressively declining the medicinal value with this situation to acquiring from the wild sources in more important recent trends bening. Reported in cresingly the antimicrobial properties of medicinal plants from different parts of the world. On this basis, the present investigation was focused on the screening of antimicrobial properties of Asystasia indica Asystasia gangetica Thunbergia alata on selected Pathogenic bacteriaThe main objectives of this work use as follow To Screen the antimicrobial properties of these plants on selected micro organisms. To determine the effectiveness of inhibition on microbes by comparing its activity with known antibiotics.

\section{Council for Innovative Research}

Peer Review Research Publishing System

Journal of Advances in Natural Sciences

Vol. 3, No. 1

editorjansonline@gmail.com

www.cirworld.com 


\section{INTRODUCTION}

'Life is gift of God'. This proverb proves that life is very precious and valuable than anything else. Although infectious diseases are the world's leading cause of premature deaths, killing almost 50000 people every day. In recent years, drug resistant to human pathogenic bacteria has been commonly reported from all over the world Radhika et al 2002.,shind et al 2003.,semic et al 2002., Rals et al 2002.,theodor et al 1991., Lopez-Garcia, et al 1992Plants have been widely used as medicine directly or utilized as a source of medicinal compounds. Traditionally used medicinal plants produce a variety of compounds of know Therapeutic properties (lyengar, 1985; Chopra et al., 1992; Harborne and Baxter, 1995). The substances that can either inhibit the grown of pathogens or kill them and have no or least toxicity to host cells are considered criteria for developing new antimicrobial drugs.

India is blessed with diversity of plant species, which have good medicinal value. Ayurveda, is of plant origin, the Indian indigenous system of medicine, dating back to the Vedic ages (1500-800 BC) has been an integral part of Indian Culture . In Ayurveda, either the whole Plant or Certain parts of leaf, flower, fruits, seeds, heartwood, stem bark, root, gum and resin, have been used for treatment of diseases. The plants over 7000 different species found in the different ecosystems are said to be used for medicinal purposes in India All India Ethnobiological Research project under the ministry of Environment and Forests, Government of India has recently estimated that nearly 8000 medicinal plants are put in used in one way or other in Preparation of medicine and medicinal Compounds in India itself.

Plants containing valuable secondary metabolites and a very wide variety of chemicals that are not directly concerned with primary metabolic Process. They extracted from plants to be used as medicinal agents, Vitamins, insecticides and fine chemicals. Those of particular chemicals are often characteristic of certain genera or families of plants.Medicinal plants produce secondary metabolites namely terpenes and Terpenoids against different pathogenic bacteria .Over the past 10 years there has been a considerable interest in the use of herbal medicines all over the world. Plants may offer new potential sources of active compounds against bacterial, fungal and viral diseases all over the world. Plants derived medicines have been a part of traditional health care in most part of the world for thousands of years and there is an increasing interest in plants as sources of agents to fight against microbial diseases (charinandy et al,1999).

This use of medicinal plants in antimicrobial activites may be attributed to the presence of the antimicrobial compounds like terpenes, essential oils, phenols, certain alkaloids and resins .Recognition of traditional systems of medicines because of their time tested efficaly without side effects and availability at low costs resulted in a great demand for medicinal plants and their products. According to semic et al 2002. theoretically there is a possibility of discovering 328 new modern drugs which are lying hidden in 3,25,000 species of the tropical rain forest, besides the 47 major modern pharmaceutical plant based drugs which are already on the world market medicinal plants therefore, form and important part of international commerce.India can capitalize on her natural inherent strengths and corner a large part of the growing trade provided we remain price competitive and ensure quality

Many medicinal plants, which were ignored in the past years, but the number of plants still formed in the wild is progressively declining the medicinal value with this situation to acquiring from the wild sources in more important recent trends bening. Reported in cresingly the antimicrobial properties of medicinal plants from different parts of the world On this basis, the present investigation was focused on the screening of antimicrobial properties of Asystasia indica Asystasia gangetica Thunbergia alata on selectedPathogenic bacteriaThe main objectives of this work use as follow

To Screen the antimicrobial properties of these plants on selected micro organisms.To determine the effectiveness of inhibition on microbes by comparing its activity with known antibiotics.

\section{MATERIALS AND METHODS}

\section{Plant material}

The following plants were collected from their natural habitats and used for their activity.Asystasia indica Asystasia gangetica Thunbergia alata at the College campus, Kodaikanal in Tamil Nadu.

The plants were shade dried at ambient Temperature $\left(31^{\circ} \mathrm{C}\right)$ and the dried materials were crushed into fine powder using an electric blender.

\section{Extract preparation}

$100 \mathrm{~g}$ of dried powder materials of Leaf, Stem, Root, Tuber were soaked separately in $500 \mathrm{ml}$ of each solvent viz. ethanol, chloroform and petroleum ether in conical flasks. Each mixture was stirred at $24 \mathrm{hr}$ using sterile glass rod. It was kept for $72 \mathrm{hrs}$. At the end of $72 \mathrm{hrs}$ each of the extract was passed through the Whatman No.1 filter paper and the filtrates were concentrated by opening the cover to $1 \mathrm{hr}$ at room temperature in order to reduce the volume. The paste like extracts were stored in labeled screwed chapped bottles and kept in refrigerator at $4^{\circ} \mathrm{C}$. Each of the extract was individually reconstituted using minimal amounts of the tracking solvent prior to use.

\section{Microorganisms selected for study} strains were,

The microorganisms used in this study were collected from Eumic lab, Tiruchirappalli. The selected microbial 
The bacterial strains were maintained in Nutrient agar plate.

\section{Preparation of the media}

a) Nutrient agar medium

$\begin{array}{lll}\text { Composition } & - & (1 \text { Litre }) \\ \text { Peptone } & - & 5.0 \mathrm{gms} \\ \text { Beef extract } & - & 3.0 \mathrm{gms} \\ \text { Yeast extract } & - & 1.5 \mathrm{gms} \\ \text { Sodium Chloride } & - & 5.0 \mathrm{gms} \\ \text { Agar } & - & 15 \mathrm{gms} \\ \text { Distilled water } & - & 1000 \mathrm{ml} .\end{array}$

After adding all the ingredients into the distilled water boiled to dissolve the medium completely and sterilized by autoclave at $121^{\circ} \mathrm{C}, 15 \mathrm{lbs}$ pressure for 15 minutes.

\section{b) Nutrient Broth (N.B) PH 7.0}

$\begin{array}{lll}\text { Peptone } & - & 5.0 \mathrm{gms} \\ \text { Beef extract } & - & 3.0 \mathrm{gms} \\ \text { Sodium Chloride } & - & 5.0 \mathrm{gms} \\ \text { Yeast extract } & - & 1.5 \mathrm{gms} \\ \text { Distilled water } & - & 1000 \mathrm{ml} .\end{array}$

After adding all the ingredients into the distilled water boiled to dissolve the medium completely and sterilized by autoclave at $121^{\circ} \mathrm{C}, 15 \mathrm{lbs}$ pressure for 15 minutes.

The following methods were selected for antimicrobial studies:

1. Disc diffusion method

2. Streak plate method

\section{Disc Diffusion Method}

\section{Principle}

The disc-diffusion method provides a simple and reliable test in routine clinical bacteriology in order to find out the effect of a particular substances on a specific bacterium.

This method consists of impregnating small circular discs of standard filter paper with given amount of a chosen concentration of substances. The discs are placed on plates of culture medium. Previously spread with a bacterial inoculum to be tested. After incubation the degree of sensitivity is determined substances from the discs into the surrounding medium.

\section{Preparation of Discs}

Discs usually consists of absorbent paper impregnated with the compound (Plant extract). It is most convenient to use Whatman No.1 filter paper for preparing the discs. Dry discs of $6 \mathrm{~mm}$ diameter were prepared from Whatman No.1 filter paper and Sterilized in an auto clave. These dry discs were used for the assay.

\section{Procedure}

Circular discs of $6 \mathrm{~mm}$ diameter were prepared from Whatman No.1 filter paper and Sterilized in an autoclave. These paper discs were impregnated with test compounds (Plant extracts) in the respective solvents for over night and placed on nutrient agar plates seeded with the test bacterium. Preparation of the test solution of different concentration for streak plate method.

Each extract is taken for activity studies, the extracts concentration is made into solution of different concentration as give bellow.

[25\%] $0.5 \mathrm{ml}$ of extract $+1.5 \mathrm{ml}$ of distilled water

[50\%] $1 \mathrm{ml}$ of extract $+1 \mathrm{ml}$ of distilled water

[75\%] $1.5 \mathrm{ml}$ of extract $+0.5 \mathrm{ml}$ of distilled water

[100\%] $2 \mathrm{ml}$ of pure extract only. 


\section{Preparation of control}

The control was prepared with Nutrient Agar medium without plant extract. Each of above concentration was tested for antibacterial activity using the Asystasia indica Asystasia gangetica Thunbergia alataagainst test bacteriaSalmonella typhiPseudomonas aeruginosa

The plates were incubated at $37^{\circ} \mathrm{C}$ for $24 \mathrm{hr}$, after $24 \mathrm{hr}$ the zone of inhibiton around each disc was measured and the diameter was recorded. The tests were repeated 4 times to ensure reliability of the result.

\section{Preparation for control}

The control was prepared with Nutrient Agar medium without plant extract. Tested for antibacterial activity using standard antibiotic disc. i.e, ciprofloxacin.

\section{Streak plate method}

The streak plate assay was generally used to obtain discrete colonies and pure colonies. This assay was used to determine the growth inhibition of bacteria by plant extracts. A sterilized loop was dipped in the suitable organisms and streaked on the surface of already solidified nutrient agar plates with plant extracts to make a series of parallel nonoverlapping streaks. The effects of the plant extracts was expressed as the growth variation found in the Agar plates after incubation at $37^{\circ} \mathrm{C}$ for 24 hours.

The extracts used for the study were prepared namely,

\section{- Chloroform \\ - $\quad$ Ethanol \\ Petroleum ether}

\section{RESULTS AND DISCUSSION}

In our present study, the antibacterial activity of six medicinal plants namely, Asystasia indica Asystasia gangetica Thunbergia alata against the tested microorganism (Salmonella typhi, Pseudom aeruginosa) were evaluated by the disc diffusion and streak plate method using different concentration of solvents. (Mazura and Norin 1993) (Rasooli, and M,r mostofa, (2002)(Puratchi et al 2001) The results showed significantly in all plants samples.

\section{Disc diffusion method}

In effect of different solvent extracts of Asystasia indica leaf, stem and tuber on the test bacterium Salmonella typhi and Pseudomonas aeruginosa by disc diffusion method The effect of various solvents namely ethanol, chloroform and petroleum ether also with the standard antibiotics

Among the three solvents extracts used, the ethanolic solvent was found to more effective when compared to other solvents. The plant part tuber has shown higher inhibitory effect among other parts used.

The Asystasia gangetica , the results indicated that the leaf have shown better inhibition than other parts such as stem and root by each of the solvents. Antibacterial activity of Thunbergia alata showed better results in ethanolic leaf extract as well as stem than root Control plates were prepared for the comparison with the standard antibiotics namely ciprofloxacin.

\section{Streak plate method}

The effect of tuber extract in all solvents of Asystasia indica Radhika, et al 2002. On the growth of SImonella typhi and Pseudomonas aeruginosa by streak plate method The results shows that in control plate excessive growth of both bacteria was observed whereas in the experimental plates gradual increase in concentration of the extract showed decrease growth. That is at $25 \%$ concentration moderate growth was observed while in $100 \%$ concentration there was no growth. However the solvents of stem and leaf did not show any significiant effect when compared to tuber. The streaking of test organism effect on Asystasia indica in leaves, stem and root The leaf extract have shown significant effect than stem and root in all solvents of test organism. No growth was occurred in $100 \%$ concentration, while excessive growth was showed in control of both organisms.

The streaking effect of ethanolic and chloroform leaf extract of Asystasia gangetica, showed that the lower concentration itself inhibited growth of both organism, that is, at $25 \%$ concentration itself the growth was less and in $50 \%$ only trace growth was noticed on salmonella typhi whereas the Pseudomonas aeruginosa has shown no growth in $75 \%$ concentration on chloroform and petroleum ether solvent The ethanolic and petroleum ether stem extracts of Asystasia gangetica have shown gradual decrease of growth of Salmonella typhi from $25 \%$ concentration as moderate, $50 \%$ concentration with trace amount of growth. No growth was occurred in $75 \%$ and $100 \%$ concentration Pseudomonas aeruginosa have shown less growth on $25 \%$ concentration of ethanolic and petroleum ether solvents were observed.

The streaking effect of ethanolic leaf extract of Thunbergia alata showed excessive growth in $25 \%$ concentration less growth in $50 \%$ concentration, whereas no growth was occurred in both $75 \%$ and $100 \%$ concentration.

Salmonella typhi has shown insignificant effect. Chloroform and petroleum ether solvents of leaf extracts have shown identical effect in which trace growth was oserved in $50 \%$ and $75 \%$ concentration. 
Chlorofom stem extract of Thunbergia alata have shown significant effect on the growth of Pseudomonas aeruginosa indicated that trace growth occurred in 50\% concentration and no growth was found in $75 \%$ and $100 \%$ concentration than other solvents.

The results indicate that the rate of inhibition was directly proportional to the concentration of the extracts of most of the experimental plants. At lower concentration inhibition was insignificant whereas at higher concentration the growth inhibition was slightly higher.

\section{DISCUSSION}

This experimental result coincides with the results of and (Kasali, A. A., et al 2002. Mundhada and taike 2003.)(Palic et al 2002. Purohit and pruthi 2003)who studied the effect of various solvent extracts of Hygrophila stricta and Pepromia pellucida and Schotia brachypetala respectively on several bacteria. Vijayakumar et al 2003) who studied the effect of various solvent extracts of Wrightia tinctoria and Bauhinia scandens on various test bacterium also confirms the result of the present study.(Sharma and Verma 1988., Sangeetha et al 1994) who studied the effect of various solvent in extracts of different plant parts of Curcuma longa and Origanum onites on different bacteria also confirms with the present results. The effect of various solvent extracts of Entrocin Pediatric suspensionand edible plants on several bacteria by Goswami et al. (2003) and Alzoreky et al. also agree with the present experimental results.

\section{SUMMARY AND CONCLUSION}

The present experimental study concludes with the following:

1. All the experimental plants were found to possess antibacterial properties to some extend especially on few bacteria.

2. Among the plant parts used for antibacterial assay tuber, stem and leaf were found to contain inhibitory effect on the growth of test bacteria.

3. Among the solvents uses for extraction, ethanol and chloroform showed more activity than the petroleum ether solvent.

4. With regard to the microbes tested, both organisms were found to be more susceptible to the plant extracts.

\section{BIBLIOGRAPHY}

1. Kasali, A. A., Ekundayo, O., Oyedeji, A. O., Adeniyi, B. A. and Adeolu, E. O. (2002). Antimicrobial activity of the essential oil of Lantana camera leaves. Journal of Essential oil-bearing plants. 5(2): 108-110.

2. Mundhada, S. S. and Taike, P.A. (2003). Preliminary Phytochemical investigation and antimicrobial activity of fruit of Mimusops elengi Linn. National convention on current trends in herbal drugs and annual conference of Indian society of Pharma cognosy, 17-18.

3. Palic, R., Stohanovic, G., Alagic, S., Nikolic, M. and Lepojevic, Z., (2002). Chemical composition and antimicrobia activity of the essential oil and $\mathrm{CO}_{2}$ extracts of the Oriental tobacco Prilep. Flavour and fragrance Journal 17(5), 323326.

4. Purohit, Nautiyal, M.C and Pruthi, P., (2003). Antimicrobial activity of the crude extracts of Rh parviflora roxb. Known as "tinitideeek" in ayured $2^{\text {nd }}$ world congress on "biotechnological development herbal medicine", 77-78.

5. Vijayakumar, M., Govindarajan, R., Mohanorao, G.M. and Mehrotra. S., (2003), Comparative antimicrobial activity of two Aristolochia species Aristolochia

6. Indica, Aristolochia bracteata and their Isolated aristolochic acid. $2^{\text {nd }}$ world congress on "bioltechnological developments of herbal medicine". 20-22.

7. Sharma, N. and Verma, H.N., (1988). Mylotoxic activity of leaf extracts of Clerodendryum S.P. Phylto plane mycoflora of tobacco and tomato and growth of fungi. Indian journal of Mycology and Ph. pathol 23(4),88-92.

8. Sangeetha, D., Sindhu, H., Thind, S.K. and Nath, R., (1994). Effect of Tribulus terrestris on oxalate metabolism in rats. Journal of Ethnopharma cology 44,61-66.

9. Mazura Gundidza. and Norin Gaza., (1993). Antimicrobial activity of Dalbergia melanoxylon extracts. Journal of Ethnopharma cology 34, 230-234.

10. Rasooli, I. and M,r mostofa, S.P., (2002). Antibacterial properties of Thymus pubescens and Thymus Serphyllum essential oils. fitoterapia 473(3), 244-250.

11. Goswami, J.G. and Patwardhan, V.D., (2003). In vitro and bacterial activity of entrocin Pediatric suspension. A ploy herbal antidiarrhoel formulation national convention on current trends in herbal drugs and annual conference of Indian Society of Pharmacognosy, 17-18.

12. Puratchi Kody, A., Jaswanth, A., Nagalakshmi, A., Anagumeenal, P.k. and Ruckmani, K., (2001). Antibacterial activity of Cyperus rotundus Linn. Indian Journal of Pharamecutical science 63(4), 326-327.

13. Radhika, U., Prathap kumar., Geetha., Hana, P., Rao, K.N.V. and Shanmuganathan, S., (2002). Antibacterial studies of Lawsonia alba leaves. Indian Journal of Natural Products 18(1), 31-39. 
14. Shind, V.M., Singhania, S.S., Omani, R.S., Kasture, S.B. and Pal, S.C.,(2003). National Convention on current trends in herbal drugs and annual conference of Indian Society of Pharmacognosy, 17-18.

15. Semic, N., Palic, R., Vajs, V., Milosaulse Vil, S. and Diokovic, D., (2002). Compostition and antibacterial activity of Achillea asplenifolia. Essential oil research 14(1), 76-78.

16. Alzorky, N.S. and Nakahara, K., (2003). Antibacterial activity of extracts from some edible plants commonly consumed in Asia. International Journal of food microbiology 80(3), 223-230.

17. Rals, C.C., Dash, S.K. and Mishra, R.K., (2002). Antibacterial efficacy of six Indian essential oils Individually and in Combination. Journal of essential oil bearing Plants 5(2), 99-107.

18. Charinandy, m., Senthosh, C.E., Phel, R.H., Polland, G.V., (1999). Screening of medicinal plants from traditional plants from Thailand and Tobacco for antimicrobial and insecticidal properties. Journal of Ethno pharma Cology 64 , 265-270.

19. Piddock, K. J.V. and Wise, R., (1989). Resistance to qunindones and clinical Perspective Jounal of Antimicrobial Chromotherapy 23, 475-483.

20. lyengar, M.A., (1985). Study of Crude drugs. $2^{\text {nd }}$ edition College of Pharmaceutical Sciences, Manipal, 13-78.

21. Ratnakar, P. and Murthy, P.S., (1995). Allium Sativum active against Susceptible and resistant mycobacterium tuberculate H87Rr. Indian Journal of clinical Biochemistry 10,14-18.

22. Theodor Kartning, Franz Still and Franz Reinthaler (1991). Antimicrobial activity of the essential oil of young pine shoots (Picea abies L). Journal of Ethnopharma cology 35, 155-157.

23. Lopez-Garcia, R.E., Hernandez-Perez, M., Rabanal, R.M., Darias, V., Martin-Herrera, D., Arias, A. and Sanz, J., (1992). Essential oils and antimicrobial activity of two varieties of Cedronella Canariensis L. Journal of Ethno Pharmalology 36, 207-211. 